\title{
16 \\ Dry Thinking, Wet Places: Conceptualising Fluid States
}

\author{
Paul Carter
}

Development and semiotic enclosure go together. In narratives of regional development, dreams and visions belong to an earlier historical phase. As the maps are filled in and the legal and administrative structures imposed, the room for imaginative manoeuvre is correspondingly contracted. The initial El Dorado romance progressively yields to narratives of heroic geographical conquest, imperial assimilation and subsequent Ersatz identifications of place. Ersatz because, despite the rhetoric of independence and autonomy, the measures of social, economic and environmental viability remain tied to the normative values of the nation-state and the global economy. In the myth of loosely flexible renegotiations of identity and habit, the frontier plays a symptomatically ambiguous role. On one hand, it suggests a hard-andfast line, while on the other it implies a wave moving forward. Solid and fluid states coexist. Northern Australia is presented as a land of opportunity; in reality, it produces extreme bureaucratic arteriosclerosis. Depending on one's social proclivities, sustainable development requires a new model of complexification, integration and their planning, one that retains the generative myth of place making (memorably inscribed in Darwin's name).

Development refers to the unfolding of new meanings - to develop is etymologically to 'unwrap' and to unwrap a country is, presumably, to reveal its meanings. At the same time, the capitalistic and colonialist thrust towards the exploitation of the Earth's resources ensures that the meanings 
attributed to the newly occupied territories are those that translate into quantifiable benefits (economic, social and political). The generative core of the country unfuelled and unveiled through development is identified with entrepreneurial knack and technological ingenuity. The notion that the country might write back-that it possesses a cryptic script of its own, a system of sustaining inter-relations and exchanges that also produce wealth, is harder to assimilate. Because of this, the development of the new society occurs through the counter-envelopment of the environment. As the environment is progressively parcelled out, classified and demarcated for discrete acts of development, its natural capacity for development is smothered. In relation to the transformational potential of a region understood creatively, the theory and practice of Western development acts surprisingly like the surfeit of bureaucratic measures that, in other circumstances, business interests so loudly lament. The principle of laissez faire is not extended to river systems, for example, and certainly not to processes that measure change in terms of geological time.

What, then, is the endgame of development conceived as a matter of planned, strategic investment in the region's resources? While thinking about the language of development, it is impossible to ignore the mixed metaphor at work here-to develop is to unwrap, to invest is to clothe. On one hand, we strive to strip away nature's disguises (e.g. to extract mineral wealth), on the other we are driven to endow what is naked and needy with dignity, agency, grace and power. Obviously, these twinned goals of development enjoy an uneasy alliance and there is an extreme ambiguity about the way they are deployed. Investment in what is already well endowed (projects that harness the earth's mineral or energy) is not recuperative but is driven by the profit motive. In this case, investment disguises a certain lack of vision, concealing the possibility of handling where we live differently. Equally, the continuing viability of the developmental society depends on an environment that is not entirely divested of its value (through overexploitation). Whatever the societal El Dorado these practices envisage, it is clear that it will be dogged by confusion unless the language of their economic utopianism is sorted out. What - to introduce a variation on the development/investment dialectic-is the relationship between folding out (as in, folding out the map) and folding up (as in, the collapse of a business)? Is there another way of thinking about change, one in which folding out means something like spreading and folding up means an act of bending that brings formerly distant surfaces together? 
Ocean Connections, a research conversation convened as part of the Cooperative Research Network (CRN), responded to this question of thinking about development differently by relocating development both conceptually and environmentally. Conceptually, the rhetoric of development in Northern Australia embodies what I have elsewhere called 'dry thinking', where the ground of thinking is idealised as a flat, dry and featureless terra nullius available for exclusive occupation, division and development (Carter, 2008b). Ocean Connections proposed a conversation between planning, the creative arts, the ecosciences and Indigenous knowledge systems and practices that was, in contrast, characterised by 'humid thinking' (p. 76). As already implied, this proposition had a strong geographical analogue - to think more fluidly about development is also to redefine the environment of development. Instead of thinking of development in terms of separable spatial units, whose functionality is directly linked to their consistency, dryness and passivity, humid thinking would bring into play environments usually regarded as too indefinite or shifting to be of strategic value. In illustration of this, we pointed to the land/water zones of Northern Australia, the coasts, estuaries, offshore currents and inland distributary systems - these may be essential to the vitality of natural systems and the resilience of human ones, but they are largely thought about (for development purposes) in dry terms.

A dry approach to environmental management is not only conceptually and environmentally impoverished but reflects the outdated disciplinary foundations of the technical knowledge underpinning governance of the public domain. Although they obviously overlap, different federal, state and territory departments are responsible respectively for health; the environment, tourism, recreation; and infrastructure. Periodically, attempts are made to find common ground (as documented elsewhere in this book) but the 'dry' mentality, which places operational self-consistency over any consideration of large societal value, means that these overtures tend to fail. This failure rests on the larger failure of our teaching and research institutions to shoulder the task of rethinking the disciplines. Ocean Connections was a pragmatic response to this intellectual desiccation-in placing artists at the heart of discussion about alternative environmental governance practices, it accepted the argument that:

The topography of thinking is drying out. And the thinkers are implicated in this. They have dematerialized the medium of thought-language. They have tried to dry up the wellsprings of memory that inform speaking and writing, and reduce language to an instrument of rational communication. They have eliminated 
the poetic dimensions of language that allow it to flow-from one idea to another, from one mouth to another. They have taken the liquid syllables of living words and, in the presses of their arguments, dried them out like flowers between sheets of blotting paper. (Carter, 2008b, p. 77)

These general claims have a particular resonance in the context of Ocean Connections where, first, multidisciplinary approaches to fragile environment management and design already exist and where, second, the rationalisation of such approaches is often figurative or poetic. So well established, for example, is the combination of Indigenous and nonIndigenous environmental management methods and practices in eastern Arnhem that the Yolngu 'refer to the two way approach as ganma-like brackish water which combines saltwater and freshwater' (Ens., 2012, p. 47). The application of the concept of ganma to a bicultural environmental management strategy illustrates the point that intellectual fluidity brings into being different fields of action and interaction. Banduk Marika remarks, 'We do not make a distinction between land and sea in the same way as Ngapaki do when talking about country; it is all country' (Marika et al., 2012, p. 136). This country is neither dry nor wet but is the combination of these qualities. Likewise, this way of thinking about country, which habitually combines qualities rather than separating them out, is not only absorptive; it extends its sense of the world through a kind of capillary action until its realm of action and responsibility links up to universal coordinates of time and space. The Yolnguwu Monuk Gapu Wänga Sea Country Plan, subtitled A Yolngu Vision and Plan for Sea Country Management in North-East Arnhem Land, Northern Territory (Dhimurru, 2006), states:
Ancestral Spirit beings of the Yirritja and Dhuwa moieties created us and the known world - the celestial bodies, land, sea, living plants and animals. The journeys of these ancestral creators crisscrossed the sea and the land creating the land and the seascape and breathing life into the living things that inhabit it ... From these ancestral journeys and the network of important sites created across land and sea, we gain our names, our identity, and our way of life. (Verran, 2007, p. 7)

The relational philosophies of north Australian peoples find parallels around the limits of the Ocean Connections zone of interest. Originally inspired by an invitation to consider sustainable design solutions for a severely compromised river system in Chennai, and migrating to 
conversations about the sea-land governance of estates in West Sulawesi, Ocean Connections has repeatedly encountered humid geographies whose capacity to crisscross elementally distinct land and seascapes is predicated on the human analogy. Instead of positing a sharp distinction between human and non-human cultures, the middle ground of environmental exploration, exchange and care is populated with symbolic forms that provide mythopoetic proof of an ultimate reciprocity between the world and human interests. These understandings of place perceive a complexly interwoven system of relations that underwrite the vitality of the environment and that should inform everyday social praxis. In the context of a reorientation from dry, functionalist management practices towards participatory, relational and self-actualising senses of place, relational philosophies suggest how multifactorial strategies for habitat maintenance and renewal can be put in place.

In 2007, the distinguished Australian architect Greg Burgess and I were invited to conceptualise and design a bridge for the Adyar Poonga recuperative ecology project in Chennai, Tamil Nadu. This project exemplified stresses and strains between Western-style administrative managerialism and community-based cultural understandings of place with which we are quite familiar in the Top End. In writing the reverse brief, I noted some other familiar biases and omissions from the proposed recuperation strategy. Given the downstream pre-estuarine Adyar was brackish and, in particular, composed of a fractal pattern of shallow flows, porous edges and tidal meanders, it was an oversight not to articulate the character of these edges. In the classic Tamil period, the Tamil land was divided into five kinds of country. One of these was the 'Neydal, the coastal or littoral tract'. This was not simply a physiographic tract but denoted a distinctive mode of behaviour ('Tinai'), social or moral. The notion of Tinai comprised the features of the plant life as well as of the human beings, their tribes, and clans and the gods and religious ideas ... In fact, each of the regions was conceived as a total web of life in itself' (Pillay, 1975, p. 164).

This web of life ontology assumed a new significance and poignancy a few months later when the tsunami overwhelmed our project—and dumped a tent village of tsunami survivors on the beach immediately outside the heads. In this complex (multifactorial) situation of traumatic change, what was the function of the bridge? How might a bridge not span water, starting and finishing in dry land, but become something different? Yolngu people understand that the vitality of places resides in their humid 
potential to interconnect, in their possessing a track that embodies their vitality, so that places come alive through the spirit that moves across and through them. 'The two names for the open sea are the names of multiple ancestral spirits that flow along the coast to join with the waters of the open sea' (Magowan, 2005, p. 79). We are told that 'The perceptions of water are fluid and ambiguities depending on context and a person's ancestral affiliation reflecting the many faces of those looking at it' (p. 80). The Manybuynga and Rulyapa currents are forms of connectivity, not so much in-between places as stretches of vitality. They cannot be defined in terms of hard-and-fast boundaries - they cross salt and freshwater edges, walls with interiors like snakes. Moving inside themselves, the currents are the jointure of the sea, the darker colour suggesting muscular depth. Local knowledge of this kind cannot be used as a template for ecological rehabilitation elsewhere, but, in the context of Ocean Connections, it cannot help but raise important questions about the environmental assumptions underlying Western-style infrastructure renewal projects. How does a bridge become a web? How does a web flow?

Different topographies will inspire different personifications, narratives and strategies. Zerner (2003, p. 66) said this about the beliefs Mandar people of West Sulawesi hold about oceanic connections:

While the edge of the sea is haunted by a restless, ceaselessly moving female spirit, the shallow waters, reefs, coasts, and promontories are inhabited by unpredictable, shape-shifting guardians. These regions are watched over and governed by potentially cruel spirits known as the 'guardians of the points' (B.M. pukammi tanjung).

The skills needed to navigate this unpredictable anthropomorphised archipelago are also those needed to locate shoals of fish and, more generally, to manage an environment of constant change and intermittent tumult. Any suggestion that non-Western environmental philosophies such as these are quietist or perennial can be rejected — articulated in terms of energetic flows and powerful resistances, they are adept at handling crisis, riding change and negotiating the unexpected.

Translated into infrastructure provision, the developmental imperative organises investment through the mechanism of the master plan. Master plans define the spaces of operations in terms of a jigsaw of ideally flat territories. These divisions correspond to the capitalistic need to quantify opportunity, risk and return. A comparable social economy is imagined: flows are contained and enclosures of reception designed; relationships 
are discounted as existing between projects-spatial connectivity, on the other hand, is synonymous with social progress. Evidently, a fluid understanding of place making and design means far more than a late recognition of different Indigenous epistemologies (and their perhaps illegitimate appropriation). It involves a reclassification of living spaces in terms of their relational infrastructure-their active flows, exchanges, and spatio-temporally active arrangements and rearrangements. More than this, an altered conception of development involves a reinvigorated discourse of development.

To reconceptualise places actively, in terms of spiritual, social and biological reciprocities, is, in linguistic terms, to foreground analogy and metaphor. More profoundly, it acknowledges that processes of place management may be indistinguishable from outcomes. Protocols for the maintenance of fragile environments may be scarcely different from the practice of their navigation. In temporal terms, the object is not to jettison the present and bring forward the future. It is to extend the envelope of the present to incorporate the rhythmic order of time. A Sea Breeze Dreaming in Marri Ammu language from the Kimberley runs, in English, 'Oh, brother Sea Breeze, he is eternally making himself active right here and now' (Marett, 2005, pp. 27-28). The words translated in this way mean 'he makes himself active', 'he has done it forever' and 'right here and now'. Here grammatically articulated is a fluid, 'self-manifesting and eternally active nature' that corresponds to Heraclitus' Logos. Becoming is merged into the temporal extension and differentiation of the present through the performance of the singer. Asked what the Marri Ammu term translated as 'he makes himself active' meant, a leading wannga dancer, Ambrose Piarlum, 'stood up and danced its meaning. By rotating a cloth held in his hand ... he performed in that place and in that moment the self-manifesting nature of the Tjerri's wind activity' (Marett, 2005, p. 28).

A performance of this kind might be thought to be entirely local. It has the piquancy of an anecdote but cannot generate the kinds of general principle associated with planned development. In reality, it not only expresses a collective sensibility; when brought into dialogue with other cultures that identify environmental wellbeing with human selfactualisation, it makes concrete a philosophy of flow simultaneously social and environmental. To put it another way, the performative praxis is born of the place where it happens-it does without the metaphysicalist ground of Western instrumental logic (whose colonial counterpart is the exclusively held territory). The Tjerri or Sea Breeze Dreaming (ngirrwat) 
has a site and 'Both humans and non-human phenomena born of these sites are seen as incarnations of the ngirrwat' (Marett, 2005, p. 28). Because these places speak, they connect. They are ground, they do not need to be grounded. Where there are cliffs, there are caves (p. 31). The sense is of continuous production at and of that place through a concomitant act of self-actualisation. And this relational reality-in the double sense of being mediated through story and mediating passage between elements and places-produces, geographically speaking, a region of care, one defined in terms of tidal returns.

In her book Reef Passions, Allen (in press, p. 17) writes about 'Coral reef communities of land and sea' in the Mediterranean and in West Sulawesi. Noting that in early etymologies the word 'island' had nothing to do with 'isolation' but signified 'watery lands', she characterises them as formed of 'multitudinous crossings'. She goes further, imagining landfall entirely from the point of view of oceanic energy transfer. It is, as she indicates, a reversal of perspectives that dry thinkers are likely to find dizzying:

The practice of thinking water from water while suspended in the rapid churning, entrapments, disruptions and stillness of the most voluminous through flow of water on the planet occasions a perturbation of the mindscapes that conjoin human and marine dimensions. Amazingly, the currents' circumnavigation of the more than 17,000 islands, along with the underwater trenches, basins, channels, ridges, shelves, and sills, which form Indonesia, consumes so much energy that it slows the spinning of the globe. (p. 132)

From a less marine, coastal perspective, Allen describes an archipelagic reconfiguration of geographical, cultural and social relations. Hence, according to Hamzić (2012, p. 158), 'the world's largest archipelagic state' (Indonesia) exhibits a distinct 'cultural and spiritual plurality':

The turbulent tides of trading, migration and warfare have raged along their shores for centuries, moulding syncretic ethnoscapes, wherein an islandic self is dynamically negotiated between the allegiance to local narratives and the need to adjust to foreign winds, be they of Indic, Arab, colonial European or some other more or less distant origin.

It is interesting to compare this outlook with the continentalist definition of Australian identity prevalent in Australia's political rhetoric and media stereotypes. 'Archipelagic thinking', in Glissant's (1997, p. 31) formulation: 
flows along with the course of our worlds. It borrows from their ambiguity, fragility, and derivativeness. It accepts the practice of détour, which is neither escape nor renouncement ... Is it to renounce self-government? No, it is to accord with that which, from the world, has diffused into the archipelagos precisely, the diversities in expanse, which nevertheless gather the shores and marry the horizons.

Fluid relations correspond to the humid constitution of the archipelagic environment. They stem from a classification of country that respects its amphibious nature, and that aligns its cultural, social and political practices with the creative turbulence of currents, tides, flows and their multitudinous crossings. As Langton (2006, p. 154) writes in another context, 'Along with other features of the natural world, the estuarine zone is not just a bio-physical feature, but a metaphorical reference to knowledge'. Sullivan (2014, p. 161), noting that in the Yawuru community of Broome 'Use of land is not distinct from use of the sea', emphasised the complementarity of environmental and social behaviour:

Off the coast there are areas of shallows stretching for several kilometres out to sea which are mud flats at extreme low tides and permit wading to reefs and sandbars. It is an area, then, where water, salt and fresh, is a constant, and constantly changing features of the people's lives. (pp. 161-162)

Responsive to these circumstances, 'the adaptation favoured by the Yawuru is flexibility in the distribution of land and sea rights supported by an ideology of relatedness and common property among those of the same and related languages' (p. 162).

In the context of a developmentalist discourse, these countercultures and counter-environments represent a significant choice. The political geography of the archipelagic mindset can be ignored and each community land/seascape treated as an isolated challenge to dry-style development. Alternatively, a different understanding of the meaning of development can be fostered, a capacity to work with and alongside what is already changing, self-renewing and related. The fragile environments of the nation-building infrastructure program are products of that program. They are the supplement of water-related environments, communities and traditions that resist enclosure and the desiccation of abstract planning. They resist government from a distance in favour of a tidal arrangement of differences, one that habitually expresses itself in properly performed 
meetings. In terms of a new approach to planned place making, one that recognises the strength and fragility of humid regions, much can be learnt from the educative function of the Yolngu Garma festival. For the space of potential to be realised, for Garma to become an event place 'where ideas are shared and negotiated in order to facilitate agreement', there needs to be an intensification of interests and alignment. This notion is conceptualised in the Yolngu term galtha:

[a] connecting spot ... a spot where people make solid contact with the earth, when they have been brought together from different places, and now they are having a discussion together to agree on a plan of action. Anywhere there is ceremony, there will be galtha. Every ceremony must be different, because its art lies in creating that ceremony to specifically reflect the participants and the place and the time. (Marika-Munnungirritj \& Christie, 1995, p. 59)

Per Christie (2007), 'Galtha is at once a moment and a place, a process and a manifestation' (p. 74), 'While a ceremony has a galtha, so can individuals have their own Galtha when they become truly themselves in line with ancestral imperatives' (p. 75).

Here we can reasonably touch on the issue raised later in this volume, the challenge of developing appropriate planning frameworks for the development of Darwin Harbour. In this case, instead of anticipating the discussion about scaled-up local knowledge models and their application to the production and governance of regions of care, we might ask what role a distinctively coastal (or estuarine) sensibility might play in the design of a zone such as this, of obvious strategic value but archipelagic in its humid constitution. One approach might be educative- to design a consultative process where people with convergent interests are brought together from different places, not simply to confer on the future of this place but to relate their own experience. A practical example of this approach is the link the Ocean Connections project has made to the Mellon Foundation-supported Changing Humanities Centers and Institutes/Integrative Graduate Humanities Education and Research Training (CHCI-IGHERT) program Indigeneity in an expanded field: Transnationality, migration and human/non-human belonging. ${ }^{1}$ Indigeneity, this initiative contends, is due for redefinition and the scope of its meaning

1 See Müller \& Vuletić (2014) for a report on the September 2014 workshop held at the University of California, Santa Cru. 
expanded. Supporting a 'problem-based approach to research, applicable to problems of profound human significance which cannot be definitively resolved by more knowledge or technical measures, but which demand ongoing debate, reinterpretation, reflection on values, and adaptation', this program promotes new alliances between transnational institutions and movements operating across borders and newly emergent transnational networks of Indigenous people themselves (CHCI-IGHERT Program Proposal and Pilot Project, 2014-16).

Another approach, also educative, embodies the ethics and aesthetics of fluid states in the design of a facility that acts as a filter, a meeting place of alternative strategies for the definition, representation, design and maintenance of fragile environments. In this context, Ocean Connections proposes to capture the wealth of material it has generated under the CRN arrangement in Pearl, a virtual exhibition space that also exists as the design concept for a physical building, originally commissioned for construction at the Darwin Waterfront by the Darwin Waterfront Authority. ${ }^{2}$ By developing Pearl as a digital facility or online museum, a methodological relationship is established between the themes of the creative research projects exhibited in the virtual gallery and the way these themes are conceptualised, narrated and related. The resulting virtual walk-through of approximately concentric corridors models a knowledge that emerges incrementally in response to the visitor's route. Repeated walk-throughs can be said to perform the process of interfolding different understandings of place. Like the accumulating laminations that form Pearl, concomitant acts of exploration, reflection and renewal draw the visitor-researcher into the path of their own responsibilities.

A work like Pearl conceptualises the coast differently-agreeing with Langton's (2006, p. 154) remark that 'the estuarine zone is not just a biophysical feature, but a metaphorical reference to knowledge', it translates this insight into design terms. To go back to the invitation to design a bridge for the Adyar Poonga project, we argued there that any bridge should be conceptualised as a passage.

The form of the Adyar estuary is the rationalisation of fluidity. The mingling fresh- and salt-water of estuary produces a complex system of water currents. This operates at different and overlapping temporal scales (daily, seasonal, intermittent), and produces

2 See www.materialthinking.com.au for a visual summary of the project. 
a comparably shifting land-water border. So-called 'Quibble Island' was in pre-colonial times not an 'island' but a network of creeks - inter-tidal channels. Relics of this distinctively estuarine environment survive in the low spits in the main river. (Material Thinking, 2007, p. 1)

Further, reimagined as an act of casting, the bridge could be fluid (see Carter, 2002, pp. 140-143, for the 'opening' and 'closing' of the river; see Carter, 2008a, pp. 173-202, for a developed discussion of humid edge design). Referring to the existing bridge built in the colonial period, we wrote:

\section{When the Elphinstone Bridge was thrown across the Adyar River, the outrage to the river gods can only be imagined: the bridge may have 'opened' a land passage but it 'closed' the passage of water and desecrated the sacred economy of continuous transformational flux associated with life-giving water. To reverse this imprisonment, we need to remake the bridge in the form of a net. (Material Thinking, 2007, p. 2)}

Place as passage, self as other or spirit double, orientation as authority and responsibility - these are perceptions of place integral to life in the archipelago. And, in practical terms, they focus attention on the coast, its conceptualisation and inhabitation. An idea of place as a boundary ecology emerges, the wet/dry boundary as a filtration system in which flux is endowed with a network character, as if it could be imagined as a double figure integrating wall and way, fence and flow (see Forman, 1995, p. 82ff, for the concept of 'boundary ecologies' in ecological discourse). The architecture of passage is characterised by knots where different story lines do not simply meet but entangle, hybridise or otherwise activate a principle of mere coincidence to improvise a chiasmatic or riddling formation. To riddle is to speak enigmatically, to veil senses - it is also to sift coarse material. The act of sifting serves to preserve data that do not conform, which for this reason hold the potential to attract new associations or revive old, neglected ones. In design terms, data of this kind are forms that may look strangely familiar but that resist identification. Such forms serve as hinge works, mediating between different physical states, diverse story lines and cultures of settling. In the context of designating a boundary, ecology poles have this function-stylised islands, mooring posts, palisades, sticklike figures, gills and nets-they are twinned in this typology with hollows, bays, ears, shells and other sail-like receptacles materialising the history of passage. 
It is evident that these signatures of passage localise, materialise and connect, but the sense of place they might incubate does not correspond to the 'place making' rhetoric of the master planned urban environment. The inhabitant of this networked place experiences the suspension of settlement, the creative and recreative potential of passage to produce out of chiasmatic events ambiguous settings. These offer creative templates not for the restoration of invariant cultural stereotypes but for things to take place. Staged here is the setting of exchange rates and the shadows cast by the processes of filtering, selecting, classifying and quarantining essential to the constitution of stable forms and identities. These are clearly choreographies with a global application, but they educate not by leading out from the neighbourhood but by marking and re-marking exploratory sentiers amid it. These sentiers are not paths yet. In fact, they may never evolve into signposted ways through the labyrinth. Passage here will have the same oscillatory nature as breathing; always timed and placed, always expressive, relational, dependent and poised between inspiration and expiration. Such emotionally engaging networks of sentiers as these suggest what Hokari refers to in Gurindji philosophy as the 'Right Way' — where a design is ethical not because it successfully cites traditions associated with the place but because it rightly orients people, teaching them 'how to look after this created world' (Hokari, 2005, pp. 216-217).

In encouraging dialogue between Indigenous place-based knowledge systems, and between these and the frontier rhetoric of development, Ocean Connections aspires to inaugurate a new orientation. In this, environments classified as fragile or, indeed, as lacking clear identity not only come into view as primary sites of cultural and biological biodiversity, they assume an ontological and epistemological value. They ground human relations differently, archipelagically. They correspond to forms of governance that are flexible, performative, localised but regional. The potential of this reconceptualisation to influence the political, administrative and legal cultures whose dry thinking currently dominates Northern Australia's development remains to be seen. The constructive critique will need to be pursued directly, through the demonstration of alternative approaches to the theory and practice of place making, and indirectly through the application of humid thinking to such inter-related areas as archipelagic geographies and performative, relational governance practices. 


\section{References}

Allen, J. (in press). Reef passions: Postcolonial aesthetics between coral reefs.

Carter, P. (2002). Repressed spaces: The poetics of agoraphobia. London, England: Reaktion Books.

Carter, P. (2008a). Dark writing, geography, performance, design. Honolulu, HI: University of Hawai'i Press.

Carter, P. (2008b, Winter). Trockenes Denken: vom Verlust des Wasserbewustseins und von der Poesie des Fluiden [Dry thinking: On praying for rain]. Lettre International, 76-81.

Christie, M. (2007). Yolngu language habitat: Ecology, identity and law in an Aboriginal society. In G. Leitner \& I. G. Malcolm (Eds), The habitat of Australia's Indigenous Languages: Past, present and future (pp. 57-78). Berlin, Germany; New York, NY: Mouton De Gruyter.

Changing Humanities Centers and Institutes (CHCI)/Integrative Graduate Humanities Education and Research Training (IGHERT) Program Proposal and Pilot Project. (2014-16). Indigeneity in an expanded field: Transnationality, migration, and human/non-human belonging. University of California, Santa Cruz, 2014-2016.

Dhimurru. (2006). Yolnuwu Monak Gapu Wana sea country plan: A Yolngu vision and plan for sea country management in North-East Arnhem Land, Northern Territory. Dhimurru Land Management Aboriginal Corporation.

Ens, E. (2012). Conducting two-way ecological research. In J. Altman \& S. Kerins (Eds), People on Country: Vital landscapes, Indigenous futures (pp. 26-64). Sydney, NSW: Federation Press.

Forman, R. T. T. (1995). Land mosaics: The ecology of landscapes and regions. Cambridge, England: Cambridge University Press.

Glissant, É. (1997). Traité du tout-monde. Paris: Gallimard.

Hamzić, V. (2012). Unlearning human rights and false grand dichotomies: Indonesian archipelagic selves beyond sexual/gender universality. Jindal Global Law Review, 4(1), 157-170.

Hokari, M. (2005). Gurindji mode of historical practice. In AIATSIS Conference 2002: The power of knowledge and the resonance of tradition (pp. 214-222). Canberra, ACT: AIATSIS Press. 
Langton, M. (2006). Earth, wind, fire, water: The social and spiritual construction of water in Aboriginal societies. In B. David, B. Barker \& I. J. McNiven (Eds), The social archaeology of Australian Indigenous societies (pp. 139-160). Canberra, ACT: Aboriginal Studies Press.

Magowan, F. (2005). A sea has many faces: Multiple and contested continuities in Yolngu coastal waters. In L. Taylor, G. K. Ward, G. Henderson, R. Davis \& L. A. Wallis (Eds), The power of knowledge: The resonance of tradition (pp. 74-85). Canberra, ACT: Aboriginal Studies Press.

Marett, A. (2005). Songs, dreamings \& ghosts: The Wangga of North Australia. Middletown, CT: Conn Wesleyan University Press.

Marika, B., Munyarryun, B., Munyarryun, B., Marawili, N. \& Marika, W. (2012). Ranger djama? Manymak! In J. Altman \& S. Kerins (Eds), People on Country: Vital landscapes, Indigenous futures (pp. 132-145). Sydney, NSW: Federation Press.

Marika-Munnungirritj, R. \& Christie, M. J. (1995). Yolngu metaphors for learning. International Journal of the Sociology of Language, 113(1), 59-62.

Material Thinking. (2007, 29 August). 'Adyar Poonga: Creative Inceptions 2', $1-3$. Available from the author.

Müller, E.-M. \& Vuletić, S. (2014). IGHERT Project Workshop at the Institute for Humanities Research. University of California, Santa Cruz, 19-20 September. Retrieved from www.uni-giessen.de/faculties/gcsc/newsboard/ighert-projectworkshop

Pillay, K. K. (1975). A social history of the Tamils (Vol. 1). Madras, India: University of Madras.

Sullivan, P. (2014). Salt water, fresh water and Yawuru social organization. In N. Peterson \& B. Rigsby (Eds), Customary marine tenure in Australia (pp. 159-180). Sydney, NSW: Sydney University Press.

Verran, H. (2007, 29-31 August). Contemporary Australian NRM as naturel culture dichotomy amnesia. How can we do politics of nature without politics or nature? Paper presented at Performing Nature at World's Ends, Department of Social Anthropology, University of Oslo, Norway.

Zerner, C. (2003). Sounding the Makassar Strait: The poetics and politics of an Indonesian marine environment. In C. Zerner (Ed.), Culture and the question of rights: Forests, coasts, and seas in Southeast Asia (pp. 56-108). Durham, NC: Duke University Press. 
This text is taken from Leading from the North: Rethinking Northern Australia Development, edited by Ruth Wallace, Sharon Harwood, Rolf Gerritsen, Bruce Prideaux, Tom Brewer, Linda Rosenman and Allan Dale, published 2021 by ANU Press, The Australian National University, Canberra, Australia. 